\title{
OS ESTUDOS SOBRE QUADRINHOS E A CONSOLIDAÇÃO DE UMA GRAMÁTICA DO GÊNERO
}

\author{
THE STUDIES ABOUT COMICS AND THE \\ CONSOLIDATION OF A GRAMMAR'S GENRE
}

\section{LOS ESTUDIOS SOBRE CÓMICS Y LA CONSOLIDACIÓN DE UNA GRAMÁTICA DEL GÉNERO}

${ }^{1}$ Doutor em Letras pela Universidade Federal de Juiz de Fora (UFJF). Professor adjunto da Universidade Federal do Amapá (UNIFAP). E-mail: rararafaels@yahoo.com.br 
RESUMO: O presente artigo tenta mapear não apenas alguns pontos importantes da cronologia dos estudos sobre histórias em quadrinhos, mas também discute características do gênero e sua aceitação nos meios intelectuais e acadêmicos. Além disso, são especulados novos desdobramentos digitais dos quadrinhos que podem influenciar estudos futuros.

ABSTRACT: The present article attempts to map some important points in the chronology of comic book studies, and also discusses characteristics of the genre and their acceptance in the intellectual and academic circles. Besides, there is speculation about new developments in digital comics that may influence future studies.

RESUMEN: Este artículo trata de mapear no sólo algunos puntos importantes de la cronología de los estudios sobre historietas, sino discutir también características del género y de su aceptación en los medios intelectuales y académicos. Además, se especula nuevos desdoblamientos de los cómics digitales que pueden influir en estudios futuros.

PALA VRAS-CHAVE: Quadrinhos; Cronologia; Texto; Imagem.

KEYWORDS: Comics; Chronology; Text; Image.

PALABRAS CLAVE: Cómics; Cronología; Texto; Imagen.

Desde sua organização gráfica, passando pela mescla entre imagens e textos, podemos elencar diversas características das histórias em quadrinhos que distinguem a singularidade desse gênero como algo mais que um "primo pobre do cinema" ou "coisa de criança”. Acusaçóes pautadas em mero senso comum têm sido gradativamente substituídas pela compreensão de que os quadrinhos têm uma tradição rica (para além das histórias de super-heróis ou do segmento infantil), além de um amplo (e singular) potencial comunicativo.

Enquanto a indústria atual tende a ampliar a circulação dos quadrinhos - seja pelos filmes de heróis, inseridos no filáo comercial cada vez maior da cultura geek, seja pelos eventos especializados cada vez mais frequentados -, podemos observar paralelamente o crescimento quantitativo e qualitativo de estudos sobre quadrinhos. Neste artigo, iremos 
apresentar alguns momentos marcantes dos estudos que envolvem o potencial e a gramática dos quadrinhos, buscando refletir sobre a importância de se delimitar e aprofundar tais pressupostos.

Ainda que o presente artigo se detenha mais na cronologia dos estudos, parece-nos importante iniciar as consideraçóes assinalando aspectos orgânicos e fisiológicos envolvidos na tarefa humana de lidar com textos e imagens. Essa apreciação ajuda a compreender a relevância do entendimento histórico sobre o papel da comunicação escrita e gráfica. De acordo com Gazy Andraus, os resultados de estudos cognitivos feitos por tomografias computadorizadas mostram que nosso ensino tradicional se ampara nas informaçóes escritas, paradigma este que norteia o fazer científico convencionalizado. Salvo ocasióes específicas, as informações intersubjetivas (o que inclui a imagem) são negligenciadas nesse tipo de metodologia:

Graças à tomografia computadorizada, descobriu-se que os ideogramas da escrita chinesa são lidos distintamente pelos hemisférios cerebrais, assim como as imagens e os desenhos. A grafia fonética, por sua vez, embora tenha evoluído do desenho rudimentar, acabou ocupando o lugar quase que exclusivamente das imagens, excluindo da área científica a emoção e a poeticidade, desde que o sistema cartesiano elegeu a quimera do objetivismo como diretriz de tal sistema. A escrita fonética, inclusive, é lida pelo hemisfério esquerdo, o que corrobora a hipótese de ampliar esta modalidade em detrimento do canal direito (ANDRAUS, 2006, p. 05).

A relação entre imagens e seu potencial poético intrínseco não é nova, basta lembrar das consideraçóes de Aristóteles em sua Poética acerca do papel das figuras de linguagem no processo de comunicação. No século XX, podemos perceber uma influência dessa relação imbricada entre visual e racional (especificamente dos ideogramas) na teoria de montagem do cineasta russo Sergei Eisenstein (conhecida como montagem eisensteniana). De acordo com ele, no funcionamento de alguns idiomas orientais, a combinação de diferentes hieróglifos permite que se produzam não apenas novas palavras, mas também novos conceitos: 
A questão é que a cópula (talvez fosse melhor dizer a combinação) de dois hieróglifos da série mais simples deve ser considerada não como sua soma, mas como seu produto, isto é, como um valor de outra dimensão, outro grau; cada um, separadamente, corresponde a um objeto, a um fato, mas sua combinação corresponde a um conceito. De hieróglifos separados, foi fundido - o ideograma.

Por exemplo: a imagem para água e a imagem para um olho significa "chorar"; a figura de uma orelha perto do desenho de uma porta = "ouvir";

um cachorro + uma boca = "latir"; uma boca + uma criança = "gritar";

uma boca + um pássaro = "cantar";

uma faca + um coração = "tristeza", e assim por diante

(EISENSTEIN, 2002, p. 36).

Patrícia Borges (BORGES, 2008, p. 30) discute como há um processo de síntese provocado não apenas entre duas palavras combinadas, mas entre o silêncio que existe entre elas. Essa dialética é muito pertinente na teoria da sarjeta de Scott McLoud - ou corte gráfico, como foi proposto por Moacy Cirne (CIRNE, 2002, p. 14) -, em que o vazio entre quadros de uma HQ permite a interação mental do leitor com a obra lida (MCLOUD, 1995, p. 66-67). Ao retomar a teoria de montagem eisensteniana, Borges vincula as implicaçóes dessa dialética no meio dos quadrinhos:

O significado ou o pensamento sugerido pela poesia só pode ser compreendido através do processo combinatório entre cada uma de suas frases, forçando a mente a criar uma imagem única, uma síntese. No Japão, o silêncio é considerado a base de onde nascem as palavras, portanto, é no espaço de uma palavra à outra que residem os sentidos. É através da relação destas associações que a montagem é compreendida (BORGES, 2008, p. 30).

Contudo, é importante ressaltar que essa categoria de análise do potencial dos quadrinhos foi elaborada e sistematizada tardiamente - pelo menos, se considerarmos a história do gênero nascido na segunda metade do século XIX nos trabalhos de Rodolphe Töpffer, Willhelm Busch e Richard F. Outcault. Afinal, até que os movimentos da arte vanguardista se tornassem legitimados (poucas décadas depois do nascimento das HQs), abrindo espaço para a quebra dos valores estanques sobre literatura e grafismo, o paradigma racionalista que vigorava nos séculos XVII e XVIII ainda era o conjunto de ideias a nortear tanto críticos de arte quanto cientistas e filósofos. Esse racionalismo cartesiano privilegiava a 
palavra escrita em detrimento de suportes imagéticos e poéticos (o que ajuda a entender o motivo do descrédito dos quadrinhos durante tanto tempo):

O desenho, além de dar origem à escrita, está em todas particularidades do universo. O desenho, em si, é o projeto inicial de qualquer elaboração humana. Mesmo assim, ainda que os caracteres fonéticos partam de desenhos, seu poder informacional sobrepujou o do desenho per si, e a imagem ficou desvalorizada, por longo período, no que se refere à transmissão de informação válida, principalmente após a instauração do cartesianismo, da lógica e da razão científica que não admitia subjetividade. Não só o desenho e a imagem: a poeticidade, a expressão artística, enfim, também ficou à revelia deste processo.

Assim, as histórias em quadrinhos seminais, frutos da industrialização e da era da reprodutibilidade, embora viessem desde os primórdios da história humana com os desenhos rupestres, se viram enfraquecidas e vilipendiadas no processo do positivismo e exacerbação da ciência, por meio da escrita estritamente racional e fonética, que fomentou a exclusão da importância da imagem à psique humana no processo educacional (ANDRAUS, 2006, ps. 05-06).

Conclusão semelhante foi a do estudioso Scott McLoud, ao explicar que a força das histórias em quadrinhos se encontra justamente na fusão de textos e imagens. Em sua obra Desvendando os Quadrinhos, McLoud tenta rastrear as origens dos atos comunicativos humanos, concluindo que, nos primórdios das civilizaçóes, não havia tanta diferença entre texto (o que a semiótica saussuriana trata como um signo "arbitrário”) e imagem (símbolo) ao se registrar uma mensagem. O que ocorre é que, ao longo da história, essa distinção foi sendo mais e mais definida, intensificada, e, se tratando de eficácia comunicativa, houve diferentes valorizaçóes dadas a um ou outro aspecto:

Conforme mencionado nos capítulos anteriores, as primeiras palavras eram figuras estilizadas. A maioria destas palavras se ativeram aos seus ancestrais, as figuras. Não levou muito tempo - falando relativamente para a escrita antiga se tornar mais abstrata.

(...) Com o tempo, a maior parte da escrita moderna passou a representar apenas o som, e a perder qualquer semelhança com o visível. Com a invenção da imprensa, a palavra escrita deu um grande salto para a frente, e toda a humanidade com ela (MCLOUD, 1995, ps. 142-143). 
A partir do século XVI, quanto mais o racionalismo tomava forma e tornava-se o paradigma da mentalidade da época, o distanciamento entre texto e imagem tornava-se maior:

A palavra escrita estava se tornando mais especializada, abstrata, e elaborada, cada vez menos como figuras. As figuras, enquanto isso, começaram a se desenvolver na direçáo oposta: menos abstratas, ou simbólicas, mais representacionais e específicas. No início de 1800 , a arte e a redação ocidental se afastaram tanto quanto possível (MCLOUD, 1995, ps. 144-145).

Depois de uma jornada de 5000 anos que culminou em uma radical separação de texto e imagem, novamente houve uma aproximação entre essas duas categorias comunicativas. Apropriando-se de conceitos da semiótica, McLoud afirma que abstraçóes icônicas e não-icônicas dominaram as artes, o que gerou movimentos como o impressionismo, e, depois, as vanguardas expressionistas, futuristas, cubistas, dadaístas, surrealistas, entre outras. (MCLOUD, 1995, p. 146). Paralelamente, a palavra escrita deixava de ser mais abstrata e assumia estilos mais diretos. Sobretudo em prosa, os significados eram transmitidos de maneira mais imediatos, da mesma forma que se opera a comunicação por figuras (MCLOUD, 1995, p. 147).

$\mathrm{Na}$ cultura popular, texto e imagem se fundiam cada vez mais. Nesse período histórico, em que essa relação passava por tamanha revisão de seus pressupostos, é que nasceram as histórias em quadrinhos como as conhecemos (MCLOUD, 1995, p. 149). À luz das discussóes propostas por McLoud, é interessante pensar que, apesar de ser um gênero nascido no contexto da cultura de massa, os quadrinhos possuem um lastro histórico significativo, que consolida um processo de comunicação e expressão possível de se detectar na tradição artística.

Anos antes do estudo de McLoud, Will Eisner - outro autor de quadrinhos que foi além da prática e que se dedicou a pesquisar os fundamentos dessa linguagem - também abordou a separação entre palavras e imagens. Para ele, a separação arbitrária entre as duas competências seria válida, já que "no mundo moderno da comunicação esses dispositivos são tratados separadamente. Na verdade, eles derivam de uma mesma origem, e no emprego 
habilidoso de palavras e imagens encontra-se o potencial expressivo do veículo" (EISNER, 1989, p. 13).

O que hoje em dia compóe o meio dos quadrinhos deriva de um procedimento localizado historicamente, que é o uso de textos para explicar imagens estáticas. Eisner discute o período histórico em que as inscriçóes deixaram de ser associadas às imagens - e que coincide com o período contido na citação de McLoud da página anterior, sobre o racionalismo do século XVI:

A inclusão de inscriçôes, empregadas como enunciados das pessoas retratadas em pinturas medievais, foi abandonada, de modo geral, após o século XVI. Desde então, os esforços dos artistas para expressar enunciados que fossem além da decoração ou da produção de retratos limitaram-se a expressóes faciais, posturas e cenário simbólicos. O uso de inscrições reapareceu em panfletos e publicaçôes populares no século XVIII (EISNER, 1989, p.13).

Quando a retomada das inscrições ocorre, após o século XVIII, não envolve meramente a reinserção gratuita de um elemento outrora suprimido. De acordo com Eisner, começa a se notar uma necessidade de trazer à imagem nuances e complexidades que acrescentassem significado ao objeto apresentado. A Gestalt citada por ele é justamente a produção de sentidos a partir da fusão de duas linguagens:

Então, os artistas que lidavam com a arte de contar histórias, destinada ao público de massa, procuraram criar uma Gestalt, uma linguagem coesa que servisse como veículo para a expressão de uma complexidade de pensamentos, sons, ações e ideias numa disposição em sequência, separadas por quadros. Isso ampliou as possibilidades da imagem simples. No processo, desenvolveu-se a moderna forma artística que chamamos de histórias em quadrinhos (comics), e que os franceses chamam bande dessinée (EISNER, 1989, 13).

Ainda que o procedimento de fusão de imagens e textos seja antigo, a institucionalização da linguagem dos quadrinhos permitiu que um aprofundamento e uma gramática desse procedimento pudesse ser elaborada. É exigido que o leitor não apenas apresente competências de leitura dos textos e palavras, como também das imagens. E não apenas competências que serão exercidas sobre cada campo individualmente, mas 
envolvendo a fusão (Gestalt) desses campos entrelaçados nas narrativas sequenciais dos quadrinhos:

\begin{abstract}
As histórias em quadrinhos comunicam numa "linguagem" que se vale da experiência visual comum ao criador e ao público. Pode-se esperar dos leitores modernos uma compreensão fácil da mistura imagem-palavra e da tradicional decodificação de texto. A história em quadrinhos pode ser chamada "leitura" num sentido mais amplo que o comumente aplicado ao termo (...) As regências da arte (por exemplo, perspectiva, simetria, pincelada) e as regências da literatura (por exemplo, gramática, enredo, sintaxe) superpóem-se mutuamente. A leitura da revista em quadrinhos é um ato de percepção estética e esforço intelectual (EISNER, 1989, ps. 78).
\end{abstract}

Para que toda a comunicação dos quadrinhos se efetive, é preciso que, como na literatura, exista um pacto entre leitor e autor. Eisner assinala o pressuposto de se recorrer a uma "comunidade de experiência" compartilhada por ambos.

É preciso que se desenvolva uma interação, porque o artista está evocando imagens armazenadas nas mentes de ambas as partes.

O sucesso ou fracasso desse método de comunicação depende da facilidade com que o leitor reconhece o significado e o impacto emocional da imagem. Portanto, a competência da representação e a universalidade da forma escolhida são cruciais. O estilo e a adequação da técnica são acessórios da imagem e do que ela está tentando dizer (EISNER, ps. 13-14).

A gramática dos quadrinhos envolve justamente o arcabouço de recursos disponíveis para que as intenções pretendidas se efetivem. No caso do autor, são elementos que ele deve conhecer e manejar buscando produzir efeitos comunicativos específicos. Para o leitor, são elementos que ele deve conseguir interpretar, a fim de compreender todas as camadas de sentido evocadas pela obra.

Antes das tentativas de Will Eisner e Scott McLoud de mapear e conceitualizar procedimentos próprios e peculiares do gênero dos quadrinhos, Umberto Eco também discutiu diversos aspectos das HQs em sua obra Apocalipticos e Integrados. Ele se debruça longamente sobre "uma iconografia que, mesmo quando nos reporta a estereótipos já realizados em outros ambientes (o cinema, por exemplo), usa de instrumentos gráficos 
próprios do gênero" (ECO, 1979, p.144). Ao analisar uma página da HQ Steve Canyon criada pelo autor Milton Caniff, Eco disserta sobre alguns elementos únicos dessa específica linguagem, e é esse repertório que Eco se refere como sendo uma semântica dos quadrinhos (ECO, 1979, p.145).

É importante ressaltar que existem pontos de convergência entre linguagens como o cinema e os quadrinhos, e que não podem ser menosprezados. Essas duas mídias não apenas são expressôes surgidas no mesmo período histórico, como também compartilham diversos procedimentos em comum. Por isso, é natural que alguns termos e técnicas funcionais em um desses setores possa ser pensado no outro setor. Para Eco, "o fato de que o gênero apresente características estilísticas precisas não exclui que possa estar em posição parasitária relativamente a outros fenômenos artísticos" (ECO, 1979, p. 150). Vale salientar que esse parasitismo - termo que, a princípio, parece estar impregnado de um tom supostamente pejorativo -, não é tomada pelo teórico como algo negativo:

Obviamente, num caso como esse, parasitismo não significa inutilidade. O fato de que uma solução estilística seja tomada de empréstimo a outros campos não lhe impugna o uso, desde que a solução venha integrada num contexto original que a justifique. No caso da representação do moto efetuada pela estória em quadrinhos, encontramo-nos diante de um típico fenômeno de transmigração para nível popular de um estilema que encontrou um novo contexto onde integrar-se e reencontrar uma fisionomia autônoma (ECO, 1979, p. 151).

Ainda assim, artistas como Alan Moore pensam que é necessário cada vez mais distinguir as fronteiras entre campos como o do cinema e dos quadrinhos. Esse cuidado se justifica pela confusão conceitual na qual muitos artistas ou estudiosos se veem enredados vez ou outra, na medida em que se apropriam de jargóes cinematográficos que supostamente poderiam "redimir" os quadrinhos para além de seu nicho de consumo.

O trecho que citamos de Moore pertence a um artigo escrito por ele em 1985, em que a legitimação dos quadrinhos parecia ainda distante (vale mencionar que obras do próprio Moore, como Watchmen e From Hell contribuíram nesse processo de revisão do gênero). Contudo, a republicação desse artigo em 2003 (então compilada em formato livro 
pela Avatar Press) mostra que, em alguma medida, ainda persiste certa relevância nesse tópico da busca de legitimação dos quadrinhos:

[...] in attempting to define comics, most commentators have ventured little further than drawing comparisons between the medium and other, more widely acceptable, artforms. Comics are spoken in terms of cinema, and indeed most of the working vocabulary that I use every day in panel directions to whichever artist I happen to be working with is derived entirely from the cinema. I talk in terms of close-ups, long shots, zooms and pans. It's a handy means of conveying precise visual instructions, but it also tends to define comic book values in our mind as being virtually indisguishable from cinematic values. While cinematic thinking has undoubtedly produced many of the finest comic works of the past 30 years, as a model to base our own medium upon I find it eventually to be limiting and restricting. For one thing, any emulation of film technique by the comics medium must inevitably suffer by the comparison. Sure, you can use cinematic panel progressions to make your work move involving and lively than that of comics artists who haven't mastered the trick yet, but in the final analysis you will be left with a film that has neither movement nor a soundtrack. The use of cinematic techniques can advance the standards of comic art and writing, but if those techniques are seen as the highest point to which comic art can aspire, then the medium is condemned forever to be a poor relative of the motion picture industry. That isn't good enough ${ }^{2}$ (MOORE, 2003, p. 3).

2 "no esforço de definir os quadrinhos, muitos autores têm arriscado pouco mais do que rascunhar comparações entre uma técnica e outra, mais amplamente aceitáveis como formas de artes. Quadrinhos são descritos em termos de cinema e, com efeito, muito do vocabulário que emprego todo o dia nas descriçóes das cenas para qualquer artista provém inteiramente do cinema. Falo em termos de close-ups, long-shots, zooms e panorâmicas; é uma útil linguagem convencionada de instruçóes visuais precisas, mas ela também nos leva a definir os valores quadrinhísticos como sendo virtualmente indistinguíveis dos valores cinematográficos. Enquanto o pensamento cinematográfico tem, sem sombra de dúvida, produzido muitos dos melhores trabalhos em quadrinhos dos últimos trinta anos, eu o vejo, quando modelo para basear nosso próprio meio, como sendo eventualmente limitante e restringente. Por sua vez, qualquer imitação das técnicas dos filmes pelos quadrinhos faz com que acabem perdendo, inevitavelmente, na comparação. É claro, você pode usar sequências de cenas de forma cinematográfica para tornar seu trabalho mais envolvente e animado que o de quadrinhistas que não dominam este truque ainda, mas em última análise, você acaba ficando com um filme sem som nem movimento. $\mathrm{O}$ uso de técnicas de cinema pode ser um avanço para os padróes de escrever e desenhar quadrinhos, mas, se estas técnicas forem encaradas como o ponto máximo ao qual a arte dos quadrinhos possa aspirar, nosso meio está condenado a ser eternamente um primo pobre da indústria cinematográfica. Isso não é bom o bastante" (tradução de Fernando Aoki. In: https://alforje.wordpress.com/tag/escrita/. Acessado em 29 de fevereiro de 2015). 
$\mathrm{Na}$ medida em que fazer e publicar quadrinhos torna-se cada vez mais uma atividade acessível - quer seja pela proliferação de editoras pequenas, pelos custos de edição mais em conta, ou pelo acesso a materiais de qualidade, e mesmo às possibilidades digitais de se fazer HQs pelo computador e divulgá-las na internet - percebemos que uma quantidade enorme de autores em todo o mundo consegue alargar profundamente as definiçóes outrora convencionalizadas para se pensar o gênero da arte sequencial. Tanto os críticos quanto os leitores têm tido dificuldade de acompanhar todo o material relevante que é constantemente publicado, ano após ano, em um volume crescente, e cujo saldo revela uma geração de novos autores conseguindo acrescentar e atualizar elementos à história dos quadrinhos.

Estudos como os de McLoud, Eisner e Eco (além de outros que não nos detemos por questôes de espaço, como os de Thierry Groensteen, Daniele Barbieri, ou dos brasileiros Waldomiro Vergueiro e Paulo Ramos, por exemplo) permanecem como referências úteis e ainda relevantes para estudiosos dos quadrinhos. Porém, novas possibilidades tecnológicas têm afetado, em certa medida, a fruição da leitura das HQs. A mais imediata pode ser notada na leitura feita em telas de computadores ou de telefone celular (rompendo assim com o suporte do papel e tinta tradicionais). Temos aí já alguns pontos que devem ser considerados, como a perda da influência do papel e de critérios editoriais tradicionais na estrutura dos quadrinhos. Os monitores, em certa medida, uniformizariam a apresentação das HQs feitas para circular exclusivamente no ambiente digital.

E essa seria uma mudança até mesmo tímida, ou sutil, diante de muitas outras. Diversos autores têm produzido quadrinhos animados (como gifs), quadrinhos com trilha sonora em tempo real, HQs que otimizam as barras de rolagem de sites e blogs, e até mesmo quadrinhos que simulam tridimensionalidade. Essas possibilidades, citadas no presente artigo de maneira esparsa, surgem aqui como um preâmbulo de mudanças drásticas no gênero dos quadrinhos, que irão suscitar novos estudos e novas noçóes nos próximos anos. 
Ainda assim, os quadrinhos enquanto gênero, dotados de uma gramática e de um potencial particulares, permanecem fiéis à sua essência - algo que não se perdeu na transição para o mundo digital. A célula mater das HQs persiste, baseada no caráter sequencial e na fusão entre textos e imagens, ainda que atualizada em novas camadas de possibilidades e recursos. 


\section{REFERÊNCIAS}

ANDRAUS, Gazy. As histórias em quadrinhos como informaçâo imagética integrada ao ensino universitário. São Paulo, 2006. 1v. Tese (Doutorado em Ciências da Comunicação) Escola de Comunicaçóes e Artes, Universidade de São Paulo.

BORGES, Patrícia Maria. Traços Ideogramáticos na Linguagem dos Animês. São Paulo: Via Lettera, 2008.

CIRNE, Moacy et al. Literatura em quadrinhos no Brasil: acervo da Biblioteca Nacional. Rio de Janeiro: Nova Fronteira; Fundação Biblioteca Nacional, 2002.

ECO, Umberto. Apocalípticos e Integrados. São Paulo, Perspectiva, 1979.

EISENSTEIN, Sergei. A Forma do Filme. Rio de Janeiro: Jorge Zahar, 2002.

EISNER, Will. Quadrinhos e Arte Sequencial. São Paulo: Martins Fontes, 1989.

MCLOUD, Scott. Desvendando os Quadrinhos. São Paulo: Makron Books, 1995.

MOORE, Alan. Writing for Comics. Vol.1. Urbana: Avatar Press, 2003. 